\title{
NEPHROTOXICITY BY OVERDOSE OF ACETAMINOPHEN
}

\author{
Ilir GJERMENI ${ }^{1}$, Ergita NELAJ1 ${ }^{\circledR}$, Irida KECAJ1 ${ }^{1}$, Eliona GJERMENI ${ }^{2}$, Mihal TASE ${ }^{1}$ \\ ${ }^{1}$ University Hospital Center "Mother Teresa", Tirana, Albania \\ 2 Specialties Health Center No. 3, Tirana, Albania
}

\author{
Received 03 Nov 2021, Accepted 28 Nov 2021 \\ https://doi.org/10.31688/ABMU.2021.56.4.15
}

\begin{abstract}
Introduction. Acetaminophen (paracetamol) is a widely used drug and known as a safe analgesic and antipyretic. Hepatotoxicity is usually the first complication of acetaminophen overdose. Nephrotoxicity usually appears after liver toxicity. Most studies on this topic focused on cases of acute over dosage of acetaminophen, with fewer studies on the effects of chronic overdose.

Case presentation. We present the case of 74-year-old woman with acute kidney failure because of chronic overdose of acetaminophen and a minireview of the literature. The patient presented to the emergency unit for confusion, with altered vital parameters. She had regularly used $5-6 \mathrm{~g} /$ day of paracetamol over the previous 4 weeks because of articular pain. Acute kidney and hepatic failure were diagnosed. After specific treatment, the patient was discharged in a good condition.

Conclusions. An appropriate history of administered drugs (including those without prescription by the physician) allows the accurate diagnosis and enables a faster therapeutic management. In the case presented, hyperkalemia accompanied by syncope from bradycardia raised the suspicion of the diagnosis of acute kidney injury.
\end{abstract}

Keywords: nephrotoxicity, overdose, acetaminophen.

\section{Résumé}

Néphrotoxicité par surdosage d'acétaminophène

Introduction. L'acétaminophène (paracétamol) est un médicament largement utilisé et connu comme un analgésique et antipyrétique sûrs. L'hépatotoxicité est généralement la première complication d'une surdose d'acétaminophène. La néphrotoxicité apparaît généralement après une toxicité hépatique. La plupart des études sur ce sujet se sont concentrées sur des cas de surdosage aigu d'acétaminophène, avec moins d'études sur les effets d'un surdosage chronique.

Présentation du cas. Nous présentons le cas d'une femme de 74 ans souffrant d'insuffisance rénale aiguë à cause d'un surdosage chronique d'acétaminophène et une mini revue de la littérature. Le patient s'est présenté aux urgences pour confusion, avec altération des paramètres vitaux. Elle avait utilisé régulièrement 5 à $6 \mathrm{~g} /$ jour de paracétamol au cours des 4 semaines précédentes en raison de douleurs articulaires. Une insuffisance rénale et hépatique aiguë a été diagnostiquée. Après un traitement spécifique, le patient est sorti en bon état.

Conclusions. Un historique approprié des médicaments administrés (y compris aussi ceux sans ordonnance du médecin) permet un diagnostic précis et permet une prise en charge thérapeutique plus rapide. 


\section{Abbreviation list:}

APAP - N-acetyl-para-aminophenol

AKI - Acute kidney injury

AST - Aspartate aminotransferas@e

ALT - Alanine aminotransferase

LDH - Lactate dehydrogenase

NAPQI - N-acetyl-p-benzoquinone imine

\section{INTRODUCTION}

Acetaminophen or N-acetyl-para-aminophenol (APAP) was first introduced into medicine as an antipyretic/analgesic by Von Mering in 1893 and has been used as an analgesic for home medication for over 30 years $^{1}$. Acetaminophen is one of the most common and available analgesic and antipyretic medication worldwide and is highly accessible due to fewer side effects than any other analgesic or antipyretic drug ${ }^{2}$. It is currently recommended as first-line pharmacological therapy by a variety of international guidelines for a multitude of acute and chronic painful conditions ${ }^{3}$. Acetaminophen is an active metabolite of phenacetin, that is used for its analgesic and antipyretic properties ${ }^{4}$. The daily maximal dose of acetaminophen is $4 \mathrm{~g}$, and excessive doses between 7.5-10 g can cause hepatotoxicity ${ }^{2}$. Each year in the United States approximately $6 \%$ of adults are prescribed acetaminophen doses of more than $4 \mathrm{~g}$ /day and 30,000 patients are hospitalized for acetaminophen toxicity ${ }^{3}$. Hepatotoxicity is the most studied complication of acetaminophen overdose ${ }^{4}$; however, the extrahepatic manifestations of acetaminophen toxicity are not well described in the literature. There are several case studies reporting that an acetaminophen overdose causes acute kidney injury $(\mathrm{AKI})^{5}$. Acetaminophen is generally regarded as a safer drug regarding kidney function compared to non-steroidal anti-inflammatory drugs (NSAIDs), which are known to contribute to the development of $\mathrm{AKI}^{6}$. Previous studies suggested that renal insufficiency occurs in approximately $1-2 \%$ of patients with acetaminophen overdose $^{6}$. This percentage rises to $10 \%$ in cases of severe hepatotoxicity?

The ingestion of toxic doses of acetaminophen can cause AKI because of acute tubular necrosis of the proximal tubule, and habitual acetaminophen use may result in chronic kidney disease and end-stage renal disease from chronic interstitial fibrosis or papillary necrosis ${ }^{2}$. The excessive amounts of acetaminophen and $\mathrm{N}$-acetyl-p-benzoquinone imine (NAPQI) are excreted by the kidney and may contribute to AKI. Furthermore, the associated oxidative stress can lead to direct nephrotoxicity ${ }^{5}$.
Dans le cas présenté, une hyperkaliémie accompagnée d'une syncope de bradycardie a fait suspecter le diagnostic d'insuffisance rénale aiguë.

Mots-clés: néphrotoxicité, surdosage, l'acétaminophène.

One cohort study from Taiwan showed that the overall risk of developing AKI was about twice as high in patients with APAP intoxication ${ }^{6}$, discussing that AKI may be caused by $\mathrm{N}$-acetyl-p-benzoquinone imine (NAPQI), which is a toxic intermediate metabolite of $\mathrm{APAP}^{8}$ produced in excess by the saturation of normal metabolic pathways in the liver. Hence, the results of this study are difficult to apply to the effects of APAP at therapeutic doses.

Kanchanasurakit et a ${ }^{9}$ performed a systematic review and meta-analysis of the association between acetaminophen and renal impairment. Their results concluded that acetaminophen users without a prior history of kidney disease had a significantly increased risk (31\%) of renal impairment compared with non-users ${ }^{9}$. Therefore, attention should be paid to use of acetaminophen in patients with risk factors of nephrotoxicity.

In this article, we describe the clinical presentation of nephrotoxicity from chronic acetaminophen overdose in a low-risk patient.

\section{Case report}

A 74-year-old women patient presented to the emergency department because of a syncope at home. At admission, the patient was confused, with a blood pressure of $160 / 90 \mathrm{mmHg}$, heart rate $35 / \mathrm{min}$, respiratory rate $32 / \mathrm{min}$, pulse oximetry $95 \%$ in room air. Electrocardiogram revealed a grade III atrio-ventricular block. The laboratory emergency tests showed glycemia $185 \mathrm{mg} / \mathrm{dL}$, BUN $69 \mathrm{mg} / \mathrm{dL}$, creatinine $2.0 \mathrm{mg} / \mathrm{dL}$, aspartate aminotransferase (AST) 75 $\mathrm{U} / \mathrm{L}$, alanine aminotransferase (ALT) $60 \mathrm{U} / \mathrm{L}$, total bilirubin $0.4 \mathrm{mg} / \mathrm{dL}$, International Normalized Ratio 1.365, Na 133 mmol/L, K 7.7 mmol/L, Cl 106 $\mathrm{mmol} / \mathrm{L}$. The complete blood count was within normal limits. Her past medical history was significant for arterial hypertension controlled by angiotensin receptor blockers and hydrochlorothiazide, and type 2 diabetes mellitus controlled by insulin glargine, metformin, and glibenclamide. She had no history of alcohol abuse or renal insufficiency. The patient regularly used acetaminophen $6-7 \mathrm{~g} /$ day over the previous 4 weeks, because of articular pain. 


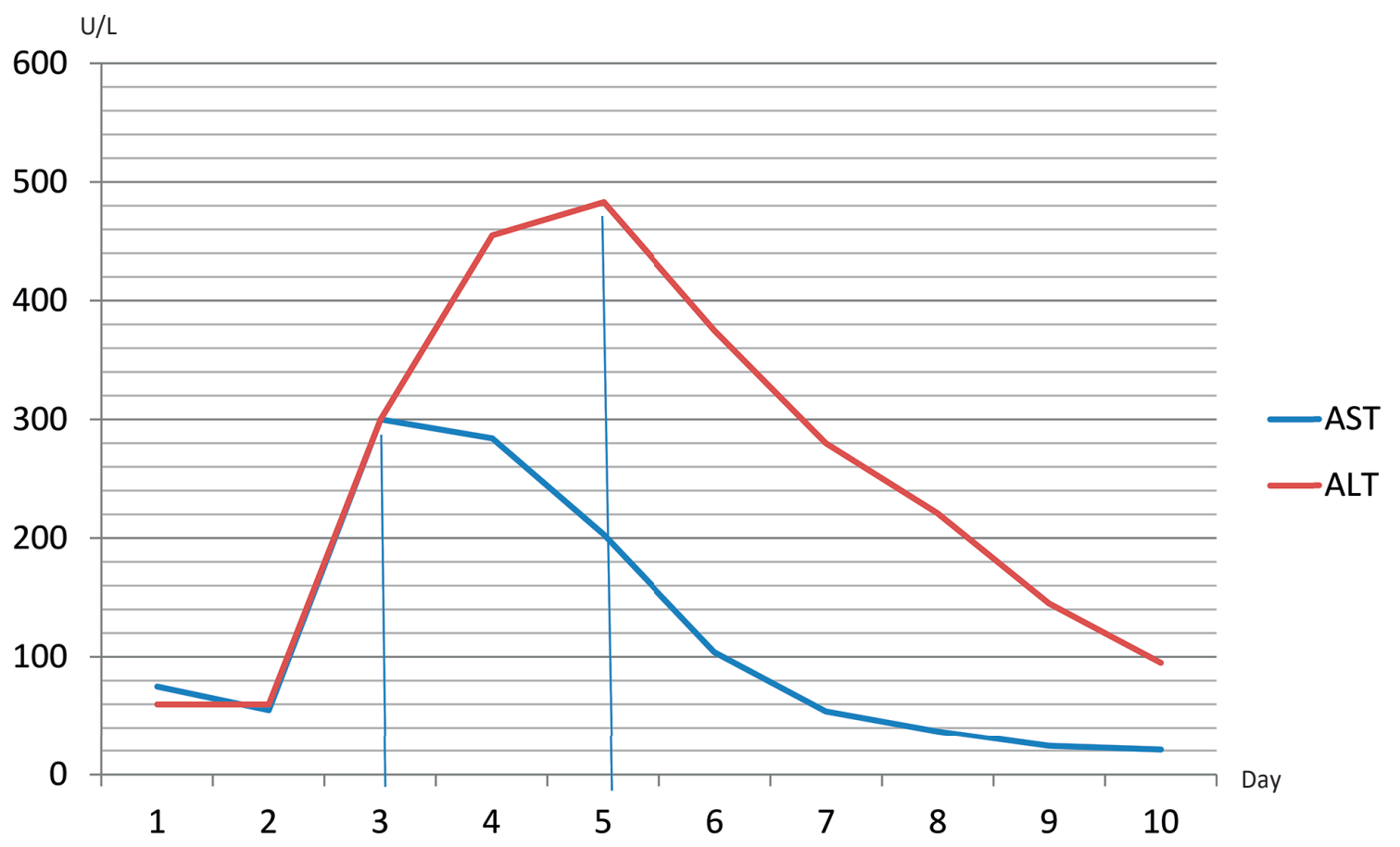

Figure 1. The evolution of AST and ALT values during hospitalization.

Table 1. Laboratory tests during hospitalization.

\begin{tabular}{|c|c|c|c|c|c|c|c|c|c|c|}
\hline Day & 1 & 2 & 3 & 4 & 5 & 6 & 7 & 8 & 9 & 10 \\
\hline Glycaemia (mg/dL) & 185 & 272 & 192 & 134 & 248 & & 286 & 181 & 216 & 214 \\
\hline BUN (mg/dL) & 69 & 85 & 86 & 74 & 60 & & 33 & 28 & & 37 \\
\hline Creatinine $(\mathrm{mg} / \mathrm{dL})$ & 2.0 & 2.3 & 2.4 & 1.7 & 1.3 & & 1.0 & 1.0 & & 0.9 \\
\hline $\operatorname{AST}(\mathrm{U} / \mathrm{L})$ & 75 & 55 & 300 & 284 & 203 & 104 & 54 & 37 & 24 & 21 \\
\hline $\operatorname{ALT}(\mathrm{U} / \mathrm{L})$ & 60 & 60 & 300 & 455 & 483 & 375 & 280 & 221 & 145 & 95 \\
\hline GGT (U/L) & & & & 30 & & 44 & 4 & & & \\
\hline $\begin{array}{l}\text { Alkaline phosphatase } \\
(\mathrm{U} / \mathrm{L})\end{array}$ & & & & 91 & & 89 & 99 & & & \\
\hline $\begin{array}{c}\text { Total bilirubin (mg/ } \\
\mathrm{dL})\end{array}$ & 0.4 & 0.5 & 0.6 & 0.5 & 0.7 & & 0.7 & & 0.6 & 0.4 \\
\hline $\mathrm{Na}(\mathrm{mmol} / \mathrm{L})$ & 133 & 135 & 143 & 138 & 136 & & 135 & 135 & & 139 \\
\hline $\mathrm{K}(\mathrm{mmol} / \mathrm{L})$ & 7.7 & 7.1 & 5.0 & 3.7 & 3.7 & & 3.4 & 3.2 & & 3.8 \\
\hline $\mathrm{Cl}(\mathrm{mmol} / \mathrm{L})$ & 106 & 103 & 99 & 97 & 95 & & 98 & 98 & & 106 \\
\hline INR & 1.365 & & & & & & & & 1.215 & \\
\hline $\mathrm{LDH}(\mathrm{U} / \mathrm{L})$ & & & 739 & & & 307 & & & & \\
\hline
\end{tabular}

Legend: References values: glycaemia 80-116 mg/dL, BUN 21-43 mg/dL, creatinine 0.57-1.11 mg/dL, AST < 55 U/L, ALT 5-34 U/L, GGT 12-64 U/L, alkaline phosphatase 40-150 U/L, total bilirubin 0.3-1.2 mg/dL, Na 136-145 mg/dL, K 3.5-5.1 mg/ dL, Cl 98-107 mg/dL, LDH 125-220 U/L.

Fluid treatment was started, with rapid insulin, glucose $5 \%$, and $\mathrm{N}$-acetylcysteine p.o. On the $3^{\text {rd }}$ day after admission the condition of the patient aggravated by the appearance of nausea, vomiting, and abdominal pain in the right upper quadrant. Biochemical tests showed glycemia $192 \mathrm{mg} / \mathrm{dL}$, BUN $86 \mathrm{mg} / \mathrm{dL}$, creatinine $2.4 \mathrm{mg} / \mathrm{dL}$, AST $300 \mathrm{U} / \mathrm{L}$, ALT $300 \mathrm{U} / \mathrm{L}$, lactate dehydrogenase (LDH) $739 \mathrm{U} / \mathrm{L}$, total bilirubin $0.6 \mathrm{mg} / \mathrm{dL}$, Na $143 \mathrm{~mol} / \mathrm{L}, \mathrm{K} 5.0 \mathrm{mmol} / \mathrm{L}$, Cl $99 \mathrm{mmol} / \mathrm{L}$; hepatitis B surface antigen and hepatitis $C$ virus antibodies were negative. In the same day, a peak of creatinine and BUN was observed (Fig. 1). Fluid rehydration continued and a second cycle of $\mathrm{N}$-acetylcysteine p.o. was repeated. In the fifth day, a peak of AST and ALT was noted (Fig. 2), and the other biochemical tests were as follows: glycemia 


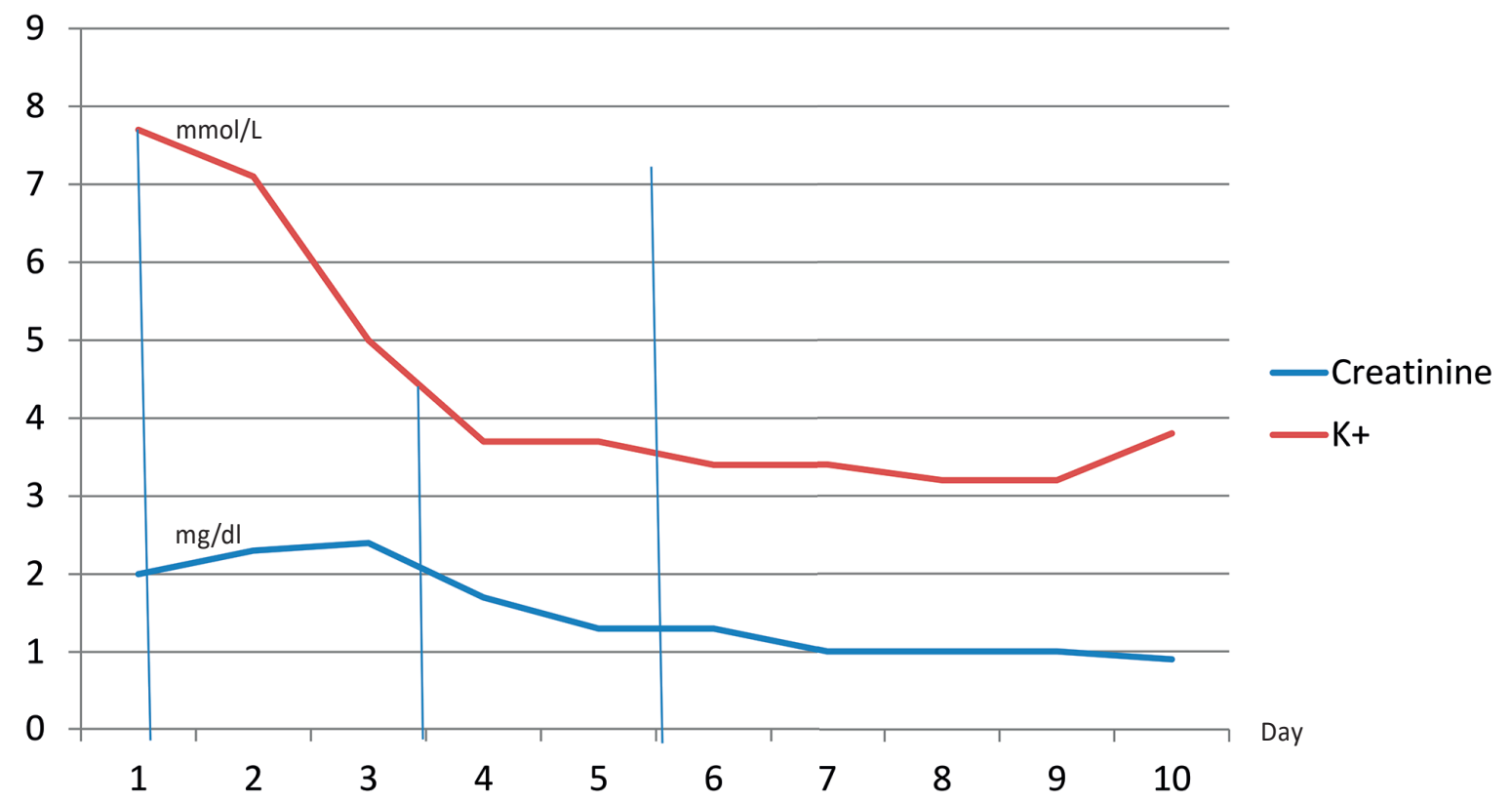

Figure 2. The peak of $\mathrm{K}+$ and creatinine on the third day of hospitalization.

$248 \mathrm{mg} / \mathrm{dL}$, BUN $60 \mathrm{mg} / \mathrm{dL}$, creatinine $1.3 \mathrm{mg} / \mathrm{dL}$, AST $285 \mathrm{U} / \mathrm{L}$, ALT $483 \mathrm{U} / \mathrm{L}$, total bilirubin $0.7 \mathrm{mg} /$ dL, Na $135 \mathrm{mmol} / \mathrm{L}, \mathrm{K} 3.7 \mathrm{mmol} / \mathrm{L}, \mathrm{Cl} 95 \mathrm{mmol} / \mathrm{L}$. During the following days, the patient continued the intravenous liquid therapy, antihypertensive and antidiabetic treatment. The patient was discharged in the $10^{\text {th }}$ day with normalized biochemical tests values. The distribution of laboratory tests during hospitalization is presented in Table 1.

\section{Discussion}

Acetaminophen is well-known for its hepatotoxicity, especially when high doses are used. The relationship between the acetaminophen dose and nephrotoxicity is not as clearly defined as hepatotoxicity. Acetaminophen-induced nephropathy may occur at lower doses than those involved in hepatotoxicity ${ }^{10}$. In a retrospective analysis of patients with acetaminophen-related nephrotoxicity registered to a poison center network database in Germany, from 1995 to 2003, 17 patients were diagnosed with renal insufficiency associated with acute acetaminophen poisoning $(8 \text { women, } 9 \text { men })^{11}$. Five (out of 17) patients developed renal insufficiency with normal liver function tests. Regarding the ingested amount of acetaminophen, detailed and reliable data were difficult to obtain as in 13 cases acetaminophen was ingested with suicidal intention and 4 patients had chronic overdose of acetaminophen. In 9 patients, a total amount of ingested acetaminophen of approximately
5,000 mg was determined. Most patients who developed renal insufficiency without concomitant hepatoxicity took only slightly higher doses and some had no potential risk factors, suggesting that nephrotoxicity may occur at lower acetaminophen doses than those that cause hepatotoxicity ${ }^{11}$. In this multicenter analysis, almost one-third of patients with renal insufficiency after acetaminophen overdose did not have concomitant hepatotoxicity. After acetaminophen overdose, renal insufficiency without hepatotoxicity may be more common than previously recognized ${ }^{10,11}$.

In our patient, nephrotoxicity occurred after acetaminophen overdose. The mechanism of this phenomenon may be related to the independent production of toxins in both organs but is insufficient $\mathrm{known}^{12}$. However, acetaminophen can be equally harmful for the kidneys, giving rise to AKI when ingested in toxic amounts ${ }^{13}$. Various mechanisms of kidney injury may be involved, such as chronic interstitial inflammation and fibrosis, thickening of the vascular wall in the kidney, renal papilla necrosis, and cortex necrosis ${ }^{14}$. The mechanisms of necrosis in both organs are similar, yet there are some subtle differences that remain unclear. Patients may present with isolated renal toxicity or in the setting of multisystem organ failure ${ }^{5}$. While the mechanisms leading to hepatic injury have been extensively studied, the molecular mechanisms of acetaminophen-induced nephrotoxicity are poorly defined ${ }^{4}$. AKI occurs in about $2-10 \%$ of patients with acetaminophen overdose and the rise in serum creatinine is usually seen two to 
five days after ingestion ${ }^{15}$. The serum creatinine attained peak levels on average 7 days post-ingestion, with a range of 3-16 days ${ }^{5}$. Most patients have a return to baseline renal function within one month ${ }^{16}$. Approximately $1 \%$ of patients require dialysis, more common in those with multisystem organ failure and comorbidities, and less likely in cases with isolated renal dysfunction ${ }^{5}$.

$90 \%$ of ingested acetaminophen is metabolized to nontoxic compounds that are excreted unchanged in the urine, $5 \%$ is excreted unchanged in the urine and the remainder is converted to a toxic compound, NAPQI, that is conjugated by hepatic glutathione and is further excreted in the urine ${ }^{15}$. When acetaminophen is ingested in a toxic amount, more acetaminophen is converted to NAPQI because the pathway to convert acetaminophen into nontoxic compounds is saturated. Since there is not enough glutathione to conjugate this excessive amount of NAPQI, unconjugated toxic NAPQI accumulates the liver. Moreover, excessive amounts of acetaminophen and NAPQI are excreted by the kidney and may contribute to kidney injury by tubular ischemia, resulting in acute tubular necrosis. The oxidative stress can lead to nephrotoxicity and decrease the amount of glutathione in the kidney $^{16}$. It is important to rule out other causes of AKI, including nephrotoxic medications and hypovolemia. Furthermore, one in vitro study revealed acetaminophen-induced apoptosis in proximal tubular epithelial cells and induced endoplasmic reticulum stress in tubular cells $s^{4}$. The results of this study support the hypothesis that acute tubular necrosis is one of the most likely mechanisms responsible for renal impairment in patients who use acetaminophen ${ }^{4}$. The risk factors associated with renal impairment in patients treated with acetaminophen were the high dose of acetaminophen, comorbidities (such as diabetes mellitus, liver failure), alcohol ingestion, and concomitant use of nephrotoxic drugs (such as nonsteroidal anti-inflammatory drugs ${ }^{9,16,17}$. Patients with these risk factors treated with acetaminophen may be at increased risk of renal impairment ${ }^{9}$. Our patient had one risk factor that can increase nephrotoxicity by acetaminophen, type 2 diabetes. The treatment is generally supportive, to avoid further kidney injury ${ }^{15}$ and includes supportive care with monitoring of renal function and hemodialysis in cases with worsening glomerular filtration ${ }^{18}$.

$\mathrm{N}$-acetylcysteine is recommended for the prevention of hepatotoxicity. Studies have shown that $\mathrm{N}$-acetylcysteine can protect against hepatotoxicity but is ineffective for preventing nephrotoxicity ${ }^{2}$. $\mathrm{N}$-acetylcysteine is effective against the replenishing glutathione stores caused by oxidative metabolite of acetaminophen and could prevent or reduce the severity of acetaminophen hepatotoxicity ${ }^{18}$. The literature supports hemodialysis for acetaminophen overdose with signs of severe toxicity, including central nervous system depression. The dose of $\mathrm{N}$-acetylcysteine should be doubled in such situations as it is also cleared by hemodialysis ${ }^{15}$. Specifically, early hemodialysis reduces the risk of irreversible kidney damage and hemodialysis dependence. In our patient hemodialysis was not necessary.

In summary, although acetaminophen-induced acute nephrotoxicity is rare, it may occur even without hepatotoxicity and the patients at risk should be monitored.

\section{Conclusions}

AKI may be the first complication of acetaminophen overdose. It may be encountered alone or accompanied by hepatic failure. Acetaminophen overdose may also occur because of long-time intake of the drug in non-very large amounts over the daily therapeutic dose. An appropriate history of administered drugs (including those without prescription by the physician) allows the accurate diagnosis and enables a faster therapeutic management. In the case presented, hyperkalemia accompanied by syncope from bradycardia raised the suspicion of the diagnosis of AKI. AKI can sometimes be a lethal condition, and patients who recovered from AKI can progress to chronic kidney disease. It is important to investigate any association between the therapeutic dose of acetaminophen and AKI, to allow a better decision making for pain management.

\section{Author Contributions:}

I.Gj. and I.K. were responsible for the diagnostic procedures, clinical diagnosis, and treatment decisions. I.Gj. wrote the manuscript, E.N adapted it for publication, and E.Gj. translated the abstract in French. All authors have read and agreed with the final version of the article.

\section{Compliance with Ethics Requirements:}

"The authors declare no conflict of interest regarding this article"

"The authors declare that all the procedures and experiments of this study respect the ethical standards in the Helsinki Declaration of 1975, as revised in 2008(5), as well as the national law. Informed consent was obtained from the patient included in the study"

"No funding for this study"

\section{Acknowledgements: \\ None}




\section{References}

1. Hegazy A, Abd Al Hameed E, El-Wafaey D, Khorshed O. Effect of paracetamol administration on the rat kidney structure: a morphological study. Zagazig University Medical Journal. 2021;27(4):567- 576.

2. Park WY. Controversies in acetaminophen nephrotoxicity. Kidney Research Clinical Practice. 2020; 39(1):4-6.

3. Blieden M, Paramore LC, Shah D, Ben-Joseph R. A per spective on the epidemiology of acetaminophen exposure and toxicity in the United States. Expert Review of Clinical Pharmacology. 2014;7(3):341-348.

4. Lorz C, Justo P, Sanz A, Subirá D, Egido J, Ortiz A. Paracetamol-induced renal tubular injury: a role for ER stress. Journal of American Society of Nephrology. 2004;15(2):380-9.

5. Mazer M, Perrone J. Acetaminophen-induced nephrotoxicity: Pathophysiology, clinical manifestations, and management. Journal of Medical Toxicology. 2008;4: 2-6.

6. Hiragi S, Yamada H, Tsukamoto T, et al. Acetaminophen administration and the risk of acute kidney injury: a self-controlled case series study. Clinical Epidemiology 2018;10: 265-276.

7. Blakely P, McDonald BR. Acute renal failure due to acetaminophen ingestion: a case report and review of the literature. Journal of American Society of Nephrology. 1995;6(1):48-53.

8. Da Rocha BA, Ritter AM, Ames FQ, et al. Acetaminophen-induced hepatotoxicity: preventive effect of trans anethole. Biomed Pharm. 2017;86:213-220.

9. Kanchanasurakit S, Arsu A, Siriplabpla W, et al. Acetaminophen use and risk of renal impairment: a systematic review and meta-analysis. Kidney Research Clinical Practice. 2020; 39(1):81-92.

10. Ozkaya O, Genc G, Bek K, Sullu Y. A case of acetaminophen (paracetamol) causing renal failure without liver damage in a child and review of literature. Renal Failure Journal. 2010;32(9):1125-7.

11. Von Mach MA, Hermanns-Clausen M, Koch I, et al. Experiences of a Poison Center Network with renal insufficiency in acetaminophen overdose: an analysis of 17 cases. Clinical Toxicology. 2005; 43(1):31-37

12. Suchismita R, Pradhan S, Gas K, et al. Acetaminophen induced kidney failure in rats: a dose response study. Journal of Biological Sciences. 2015;15(4):187-193.

13. Fored CM, Ejerblad E, Lindblad P, et al. Acetaminophen, aspirin, and chronic renal failure. New England Journal of Medicine. 2001;345(25):1801-1808.

14. Natasaputra V, Nugroho TE. The effect of paracetamol and codeine analgesic combination on creatinine levels in male Wistar rats. Diponegoro International Medical Journal. 2020;1(1): 5-9.

15. Saleem M, Iftikhar $\mathrm{H}$. A rare case of acetaminophen toxicity leading to severe kidney injury. Cureus. 2019;11(6): e5003.

16. Chen YG, Lin CL, Dai MS, et al. Risk of acute kidney injury and long-term outcome in patients with acetaminophen intoxication. Medicine (Baltimore). 2015;94:e2040.

17. Jichitu A, Bungau S, Stanescu AMA, et al. Non-alcoholic fatty liver disease and cardiovascular comorbidities: pathophysiological links, diagnosis, and therapeutic management. Diagnostics 2021;11(4):689.

18. Nekoukar Z, Moghimi M, Zakariaei Z, Fakhar M, Tabaripour R. Fulminant hepatorenal syndrome due to acetaminophen toxicity: a case report. Clinical Case Reports. 2021;9:e 04037. 